\title{
TாLE: Modeling of Drive-Symmetry Experiments in Gas-Filled Hohlraums at Nova
}

AUTHOR(S): E.L. Lindman, G.R. Magelssen, N.D. Delamater,

A.A. Hauer, and B.H. Wilde

Los Alamos National Laboratory, Los Alamos, NM 87545

L.V. Powers, T.J. Murphy, S.M. Pollaine, and L.J. Suter

Lawrence Livermore National Laboratory

SUBMITTED TO: 12 th International Conference

Laser Interaction and Related Plasma Phenomena

By acceptance of this article, the publisher recognizes that the U. S. Government retains a non-exclusive, royalty-free license to publish or reproduce the published form thls contribulion, or to allow others to do so, for U.. S. Government purposes.

The Los Alamos National Laboratory requests that the publisher Identify this article as work performed under the ausplces of the U.. S. Department of Energy.

\section{DISCLAIMER}

This report was prepared as an account of work sponsored by an agency of the United States Government. Neither the United States Government nor any agency thereof, nor any of their employees, makes any warranty, express or implied, or assumes any legal liability or responsibility for the accuracy, completeness, or usefulness of any information, apparatus, product, or process disclosed, or represents that its use would not infringe privately owned rights. Reference herein to any specific commercial product, process, or service by trade name, trademark, manufacturer, or otherwise does not necessarily constitute or imply its endorsement, recommendation, or favoring by the United States Government or any agency thereof. The views and opinions of authors expressed herein do not necessarily state or reflect those of the United States Government or any agency thereof. 


\section{DISCLAIMER}

Portions of this document may be illegible in electronic image products. Images are produced from the best available original document. 


\section{Modeling of Drive-Symmetry Experiments in Gas-Filled Hohlraums at Nova}

E.L. Lindman, G.R. Magelssen, N.D. Delamater, A.A. Hauer, and B.H. Wilde Los Alamos National Laboratory, Los Alamos, NM 87545

L.V. Powers, T.J. Murphy

S.M. Pollaine, and L.J. Suter

Lawrence Livermore National Laboratory 


\title{
Modeling of Drive-Symmetry Experiments in Gas-Filled Hohlraums at Nova
}

\author{
E. L. Lindman*, G. R. Magelssen*, S. M. Pollaine†, L. V. \\ Powerst, N. D. Delamater*, T. J. Murphy†, B. H. Wilde*, L. \\ J. Suter†, A. A. Hauer* and R. L. Kaufman $\dagger$ \\ *Los Alamos National Laboratory, Los Alamos, NM 87545 USA and \\ $\dagger$ †awrence Livermore National Laboratory, Livermore, CA 94551, USA
}

\begin{abstract}
Experiments on capsule implosions in gas-filled hohlraums have been carried out on the NOVA Laser at Lawrence Livermore National Laboratory. Observed capsule shapes are more oblate than predicted using modeling methods which agree well with experiments in evacuated hohlraums. Improvements in modeling required to calculate these experiments and additional experiments are being pursued.
\end{abstract}

\section{INTRODUCTION}

Modcling and execution of drive-symmetry experiments in gas-filled hohlraums at Nova are currently being pursued to verify the accuracy of the design tools which we use to predict target performance for the National Ignition Facility (NIF) (1). Gas-filled hohlraums are currently preferred for the NIF because gas fill reduces the wall motion and avoids hydro-coupling asymmetries. Design calculations suggest that the desired results can be achieved with $1 \mathrm{mg} / \mathrm{cm}^{3}$ of helium or an equivalent equimolar mixture of helium and hydrogen. When fully ionized this initial gas fill has an electron density of $n_{e}=0.033 n_{\text {crit }}$. Subsequent blowoff from the walls and capsule raise the electron density in some regions to values approaching quarter critical.

\section{NOVA EXPERIMENTS AND MODELING}

The capsule-implosion-symmetry experiments and modeling were carried out in scale-1 hohlraums with standard capsules (2). The initial Lagrangian 
mesh for the calculation of such an experiment is shown in Fig. 1. A scale1 hohlraum has a diameter of $1650 \mu \mathrm{m}$ and lengths between 2000 and 2800 $\mu \mathrm{m}$. The laser entrance holes (LEH) at the ends of the cylindrical hohlraum have diameters of $75 \%$ or $100 \%$ of the hohlraum diameter. The hohlraums were unlined and filled with $1 \mathrm{~atm}$ of either neopentane, propane or methane held in by a $0.65 \mu \mathrm{m}$ thick Mylar window or a $0.35 \mu \mathrm{m}$ thick polyimide window. Since one atmosphere of methane has a mass density closest to the mass density of the gas to be used in the NIF ignition design, most of our experimental data has been obtained with methane.

The symmetry of imploded capsules was varied by changing the laser pointing. The pointing is described by giving the distance from the center of the hohlraum along the axis to the point of intersection with the central ray of the incoming laser beam. As the laser pointing was varied (from 975 to $1325 \mu \mathrm{m}$ ) different hohlraum lengths (from 2000 to $2700 \mu \mathrm{m}$ ) were used to insure that the laser beams always intersected the hohlraum axis and entered the hohlraum at the center of the LEH's. The experiments were driven with shaped pulses consisting of a 1 to 2 ns foot followed by a 1 ns main pulse with a contrast ratio between 2 and 3 and a total energy of 25 to $30 \mathrm{~kJ}$.

A "standard" capsule has an inner radius of $220 \mu \mathrm{m}$ and a total wall thickness of $54 \mu \mathrm{m}$ made up of an inner layer of polystyrene of thickness $3.1 \mu \mathrm{m}$, an intermediate layer of PVA of thickness $3.3 \mu \mathrm{m}$ and an outer layer of $\mathrm{CH}$ of thickness $48 \mu \mathrm{m}$. X-ray images of imploded standard capsules were used to examine the time-integrated symmetry over the whole laser pulse.

Lasnex calculations of these experiments are being carried out as well. These integrated calculations include the propagation of the laser through the window and gas and the energy deposition in the hohlraum walls and its reradiation as x-rays. Also included are the dynamics of the window, gas, hohlraum walls and capsule as shown in Fig. 1. Loss and redistribution of the energy by stimulated scattering instabilities and other plasma effects are, however, not included.

\section{DATA AND ANALYSIS}

Fig. 2a shows Nova data and Lasnex calculations for a methane pointing scan using standard capsules. The discrepancy between Nova data and Lasnex modeling is quite apparent. Mechanisms and missing physics which might account for the discrepancy include whole beam deflection, nonlocal electron thermal transport, and stimulated scattering of the energy towards either the capsule or the inside of the end caps of the hohlraum. Before discussing work on these effects it is useful to assess the effects of the windows which hold the gas in the hohlraum prior to the shot. When they are vaporized and ionized, 


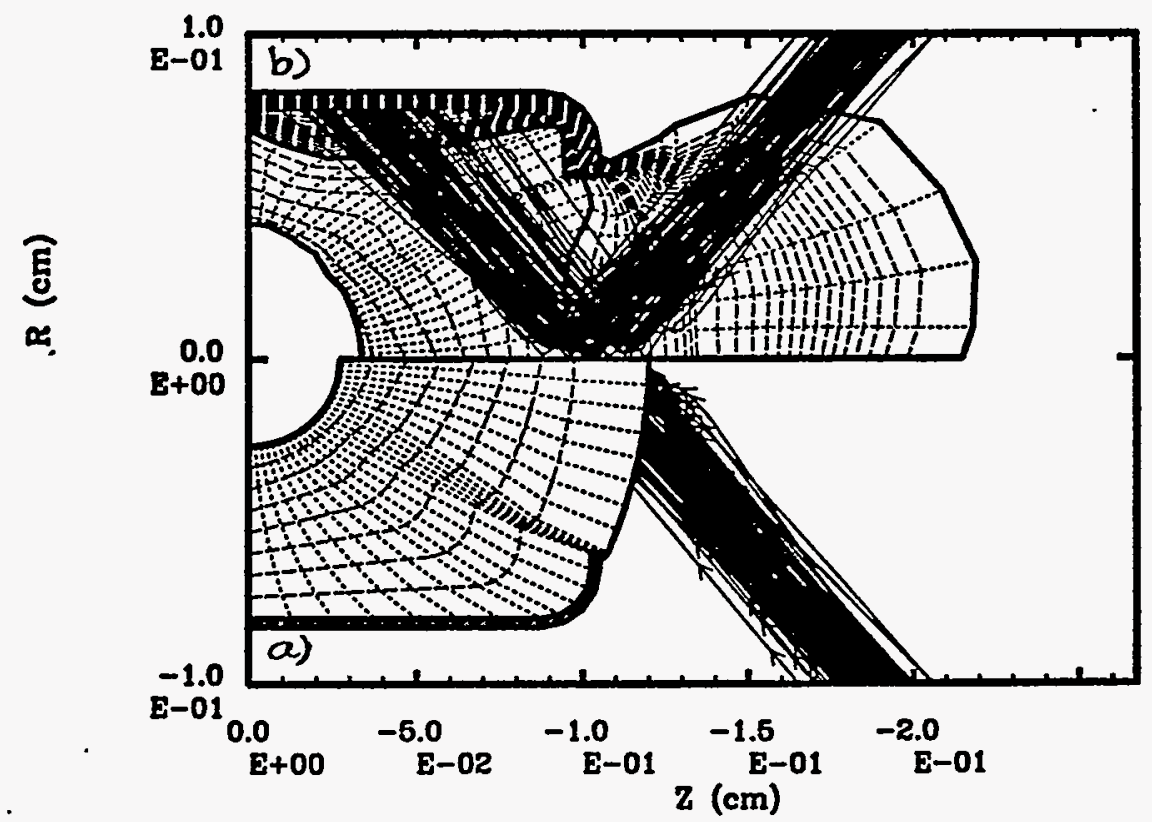

Figure 1: Lagrangian mesh at time $=0.4 \mathrm{~ns}$ compared with the initial mesh at $-0.3 n$. Initially the window and gas are opaque to the laser beams as shown on the bottom. At time $=0.4 \mathrm{~ns}$, shown on the top, the laser has burned through the window and gas and is heating the gold wall which is expanding.

they contribute plasma to the hohlraum in addition to that coming from the gas. Consequently there has been considerable attention paid to their role in these experiments.

\section{Window Plasma}

One might conclude from the data in Fig. $2 a$ that the effects of the windows are not important. Data for targets with both mylar and polyimide windows are included. The mass of a mylar window is twice the mass of a polyimide window, and, for the shortest hohlraum, the mass of the methane gas is greater than the mass of two polyimide windows by a factor of 1.5 and is less than the mass of two mylar window by a factor of 0.75 . Little difference, however, is seen in the data from the different windows suggesting that the results are not dominated by the extra plasma coming from the windows.

The opposite conclusion might be drawn from Fig. 2b. In it distortion versus gas fill are plotted to show the dependence on plasma density. The data from an evacuated hohlraum with no windows, from one filled with 1 atmosphere of methane and from one filled with 1 atmosphere of propane fall on a straight line. Also plotted at zero gas density is data from an evacuated 

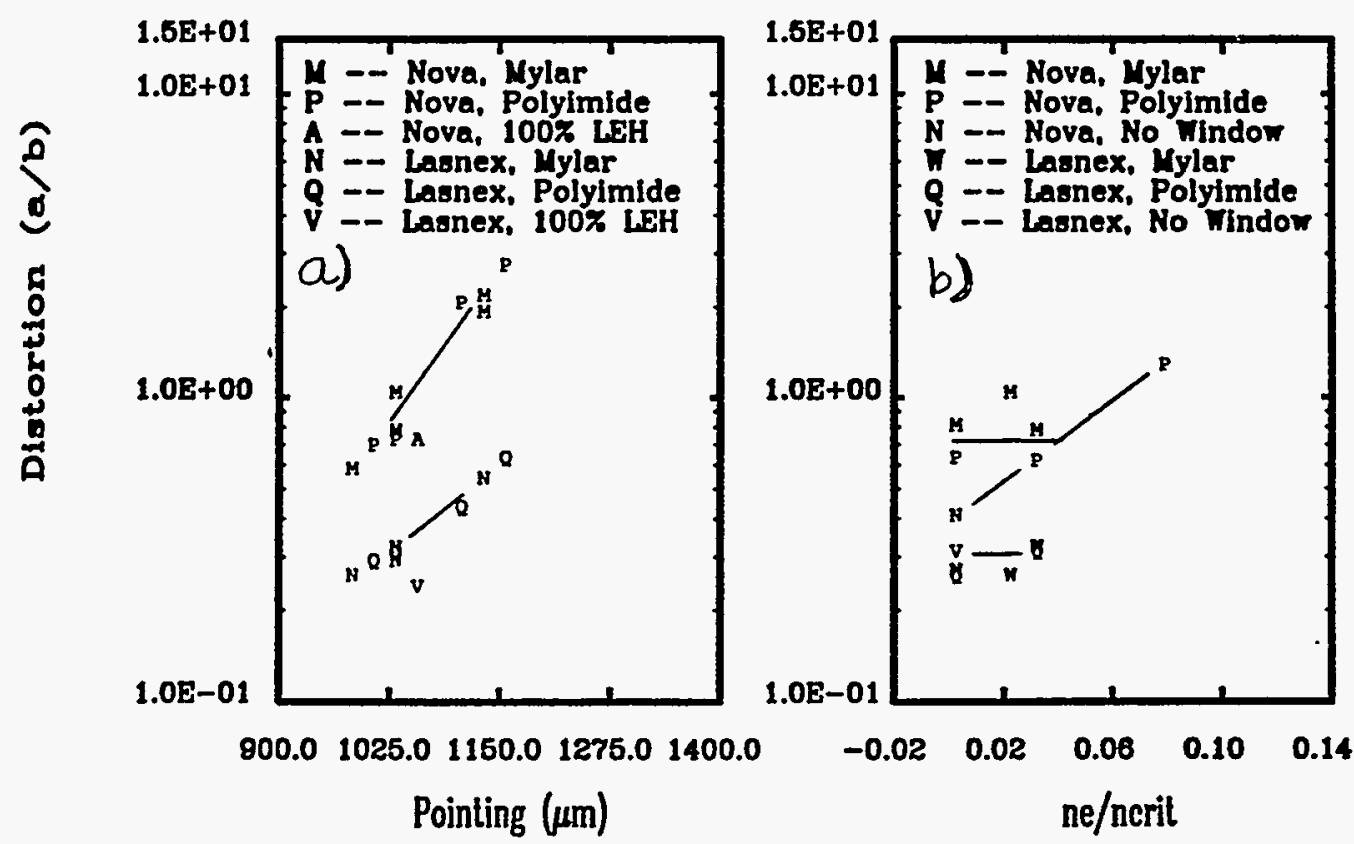

Figure 2: Imploded-capsule distortion versus pointing and density. Capsule distortion is computed by dividing the length of the semimajor axis transverse to the cylindrical axis by the length of the semimajor axis along the axis. The experimental distortions, plotted as a function of pointing for 1 atmosphere of methane on the left, and as a function of gas density at a pointing of $1025 \mu \mathrm{m}$ on the right, in general have higher values than the corresponding calculated distortions.

hohlraum with polyimide windows. The capsule distortion for latter case is similar to that obtained from the methane shot suggesting that the extra plasma from the window has an effect comparable to the methane fill.

These conflicting results may be caused by the different dynamics of the window plasmas which occur when gas is present or not. In any case the more interesting question is: What are the additional effects occurring in the experiments because of the presence of the extra plasma independent of its origin?

In contrast to the experimental data in Fig. $2 b$, the calculations show a very weak dependence on the extra plasma in the hohlraums. A discrepancy is also seen in Fig. 2a where the computed distortions, plotted versus pointing at fixed density, are quite different from the experimental data. This discrepancy was first observed in earlier experiments and modeling and was reported at the 23rd European Conference on Laser Interaction with Matter (3). In subsequent experiments and modeling we have verified the existence of the discrepancy 
and also examined some of the mechanisms and physics, missing from the calculations, which might account for the observed discrepancies.

\section{Thermal Conduction}

Electron thermal transport is computed using flux-limited diffusion in our modeling. A flux limiter of 0.05 has given better agreement with hohlraum and disk experiments in the past and has been used in these calculations. To test the possibility that the flux limiter was adversely affecting the agreement with experiment in these calculations, a set was performed in which the flux limiter was varied. The results of these calculations shown in Fig. 3b showed improved agreement of the calculated distortions of the imploded capsules with experiment. A calculation in which the flux limiter was set to 20 was used to remove it from the calculation. And the thermal diffusion transport coefficient was multiplied by 3 to test for errors in the coefficient. As shown in Fig. 3a these changes did move the results of the calculations closer to the rverimental data, but agreement was not achieved. These results support the coiterition that thermal transport is not the source of the discrepancy, but do not rule it out completely.

\section{Whole Beam Deflection}

A deflection of the laser beams away from the capsule, that is not included in the modeling, could account for the discrepancy. When this occurs the bright spot on the wall of the hohlraum heated by the laser should be displaced from its expected position. Attempts to experimentally measure a shift in the spot position have been carried out, and a shift between 0 and $100 \mu \mathrm{m}$ away from the capsule has been observed.

The beam deflection required to obtain agreement between modeling and experiment can be assessed computationally by doing calculations in which the laser beams are brought in at different angles. The results from such a sequence of calculations are shown in Fig. 3b. As the angle of incidence is changed and the spot is moved away from the capsule, the imploded-capsule distortion changes as expected. An angular deflection of $10^{\circ}$ which corresponds to a spot shift of $200 \mu \mathrm{m}$ appears to be required to match the experimental data.

\section{ACKNOWLEDGEMENTS}




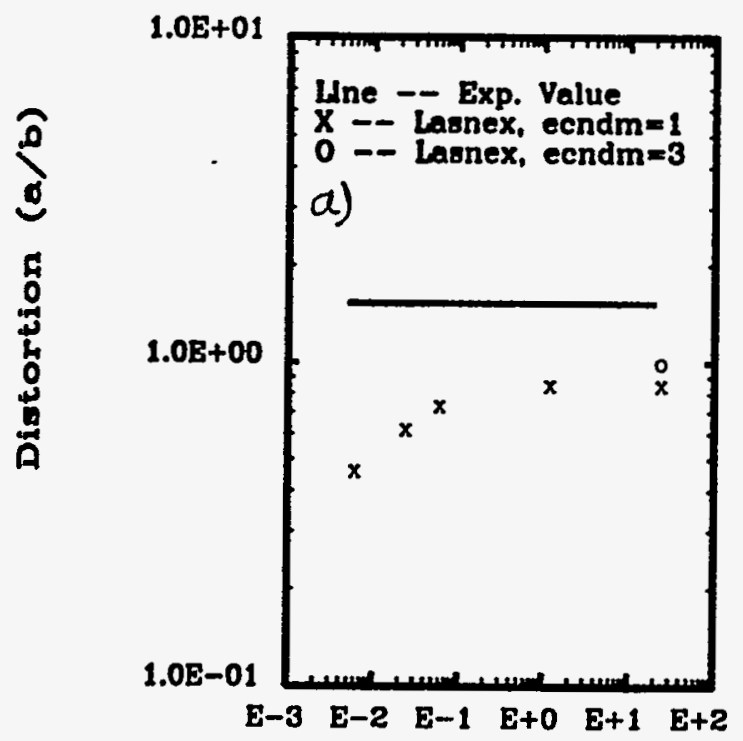

Te Flux Limiter

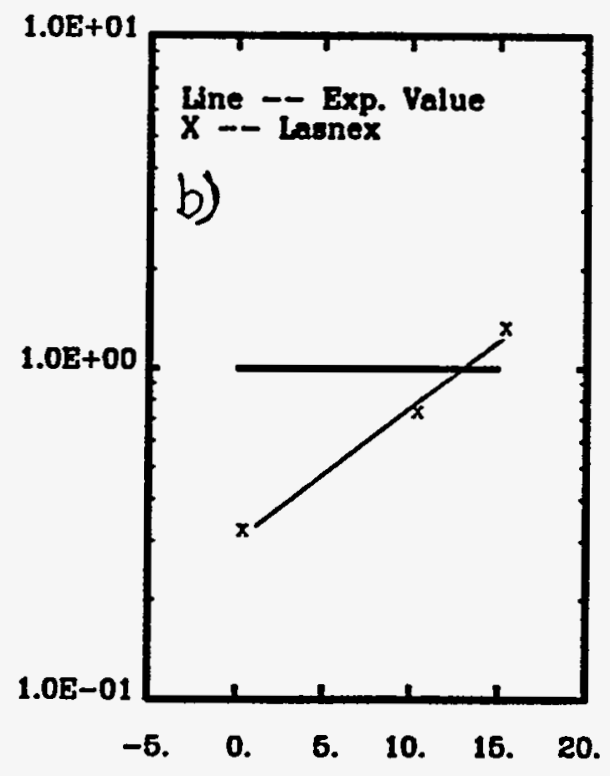

Whole Beam Deflection (deg)

Figure 3: Computed distortion vs flux limiter and beam deflection. The computed distortions approach the experimental value as the flux limiter is moved closer to free streaming, and the diffusion coefficient is made stronger. A whole beam deflection of $10^{\circ}$ or spot shift of $200 \mu \mathrm{m}$ is required for agreement of calculations with experiment.

The work was performed under the auspices of the U. S. Department of Energy under Contract No. W-7405-ENG-36 at the Los Alamos National Laboratory and under Contract No. W-7405-ENG-48 at the Lawrence Livermore National Laboratory.

\section{REFERENCES}

1. S. W. Haan, et al., "Design and Modeling of Ignition Targets for the National Ignition Facility," To be published in Physics of Fluids.

2. N. D. Delamater, et al., "Symmetry experiments in gas filled hohlraums at NOVA," To be published in the Conference Proceedings of the 12th International Conference on Laser Interaction and Related Plasma Phenomena, Osaka, Japan, April 1995.

3. E. L. Lindman, et al., "Effects of Plasma physics on capsule implosions in gasfilled hohlraums," To be published in the Conference Proceedings of the 23rd European Conference on Laser Interaction with Matter, Oxford, U. K., September 1994. 